\title{
Electrochemically assisted photocatalytic degradation of Orange II: Influence of initial $\mathrm{pH}$ values
}

\author{
Guoting $\mathrm{Li}^{\mathrm{a}}{ }^{\mathrm{a}, \mathrm{b}}$, Jiuhui $\mathrm{Qu}^{\mathrm{a}, *}$, Xiwang Zhang ${ }^{\mathrm{a}, \mathrm{b}}$, Huijuan Liu ${ }^{\mathrm{a}}$, Haining Liu ${ }^{\mathrm{a}} \mathrm{b}$ \\ a State Key Laboratory of Environmental Aquatic Chemistry, Research Center for Eco-Environmental Sciences, Beijing 100085, China \\ ${ }^{\mathrm{b}}$ Graduate School of the Chinese Academy of Sciences, Beijing 100039, China \\ Received 3 April 2006; received in revised form 13 June 2006; accepted 13 June 2006 \\ Available online 1 August 2006
}

\begin{abstract}
The effect of initial $\mathrm{pH}$ values in solution was studied in the process of electrochemically assisted photocatalytic degradation (EAPD) of an azo-dye Orange II using a $\beta-\mathrm{PbO}_{2}$ electrode modified by $\mathrm{TiO}_{2}$. The removal of color and total organic carbon (TOC) from the simulated dye wastewater was experimentally investigated at $\mathrm{pH} 2.29$ and 11.52. The degradation products were examined by means of HPLC, UV-vis and FTIR spectra analyses. Similar color removal rate was achieved at $\mathrm{pH} 2.29$ and 11.52 , but the removal of TOC at pH 2.29 was $20.0 \%$ higher than that at $\mathrm{pH} 11.52$. The dye was oxidized the most completely at $\mathrm{pH} 2.29$ than at 11.52 and 6.88 . There was a new absorbance peak at ca. $255 \mathrm{~nm}$ generated at ca. 40 min only at $\mathrm{pH} 11.52$, which was ascribed to the quinonic compounds resulted from 1-amino-2-naphtol. A reductive degradation pathway by reductive species such as active electrons was proposed, which only led to the removal of color in parallel with the oxidative degradation pathway. Hole process was proved to be the dominating process at $\mathrm{pH} 2.29$ and the effect of the reductive species was also significant at $\mathrm{pH} 11.52$. Initial $\mathrm{pH}$ values were proved to have only influenced the degradation pathways to some extent, and therefore resulted in the disparity of the removal of color and TOC. High mineralization rate was still achieved in spite of the initial $\mathrm{pH}$ values in solution due to the prevailing photocatalytic oxidation mechanism.
\end{abstract}

(C) 2006 Elsevier B.V. All rights reserved.

Keywords: $\beta-\mathrm{PbO}_{2}$ electrode; $\mathrm{TiO}_{2}$; Photoelectrocatalysis; Orange II

\section{Introduction}

Heterogeneous photocatalysis using $\mathrm{TiO}_{2}$ as photocatalyst emerged as one of the most promising destructive technology in the past decades and ever increasing attention has been paid to due to its practical and potential values in environmental protection [1-3]. Besides the inherent advantages of $\mathrm{TiO}_{2}$ photocatalysis such as low cost and simplicity, effective removal of organic pollutants was achieved in wastewater decontamination [4]. Nevertheless, it encountered difficulties of separation and recovery when $\mathrm{TiO}_{2}$ particles were used. Many studies focused on the immobilization of $\mathrm{TiO}_{2}$ particles on inert solid substrates such as sand, glass media, or resins by coating, soaking, precipitating or spinning methods [5,6]. $\mathrm{TiO}_{2}$ particles immobilized on substrates were expected to be used with high efficiency because only a limited amount of $\mathrm{TiO}_{2}$ was involved in photocatalysis.

\footnotetext{
* Corresponding author. Tel.: +86 1062849151 ; fax: +86 1062923558.

E-mail address: jhqu@rcees.ac.cn (J. Qu).
}

Recently, separation of photogenerated electrons and holes was proved to be accelerated by application of an anodic bias to $\mathrm{TiO}_{2}$ film and the lifetime of active holes and electrons was largely extended. As a result, the efficiency of photocatalysis was greatly enhanced [7]. The rate of photocatalytic degradation of 4-chlorophenol increased greatly when the $\mathrm{TiO}_{2}$ particulate film electrode was maintained at an external anodic bias $(0.6 \mathrm{~V}$ versus SCE) [6]. Anderson and co-workers [8] reported that a fast and complete decoloration of RBO was achieved as well as a significant mineralization of the dye (70\%) in a 3-h photoelectrocatalytic degradation using titanium-supported titania. Photoelectrocatalysis demonstrated its high efficiency for the degradation of organic pollutants in water and the process was widely studied so far.

However, the efficiency of photocatalytic degradation is also strongly dependent on the $\mathrm{pH}$ of the reaction solutions, especially for the dye wastewater. The $\mathrm{pH}$ values of solutions can not only change the structure of dye but also affect the reactivity of $\mathrm{TiO}_{2}$ to some extent [9]. It is well accepted that adsorption reaction occurring in photocatalysis was conducted by sur- 
face complexation. Bauer reported that Orange II molecule was linked to three $\mathrm{Ti}^{\mathrm{IV}}$ surface metallic cations through two oxygen atoms from the sulfonate group and the oxygen atom of the carbonyl group of the hydrazone tautomer [10]. The solution $\mathrm{pH}$ could affect adsorption through affecting the surface complexation reactions and the electrostatic interactions between the adsorbate and the oxide surface.

Wastewater from textile industries usually has a wide range of $\mathrm{pH}$ values. Photocatalytic efficiency should be checked in detail before any application due to the complex influence of $\mathrm{pH}$ on dye type and properties of $\mathrm{TiO}_{2}$ [2]. Therefore, it is worthwhile to make clear under which reaction media of $\mathrm{pH}$ the highest efficiency can be obtained. Nevertheless, few experiments were employed to scrutinize the different degradation performances at different initial $\mathrm{pH}$ values in detail, which may be very interesting all through the study. Besides, the higher removal of color was observed at $\mathrm{pH} 2.0$ and 12.0 as compared with that at $\mathrm{pH} 6.8$, but the removal of TOC varied in spite of the initial $\mathrm{pH}$ values in our previous study [11]. Hence, the further study is needed to figure out the effect of the initial $\mathrm{pH}$ values in solution.

The purpose of this research is to investigate the effect of the initial $\mathrm{pH}$ values in solution on the degradation of the dye during electrochemically assisted photocatalytic degradation (EAPD). The removal of color and TOC was intentionally compared between the final solutions at $\mathrm{pH} 2.29$ and 11.52. The degradation products were scrutinized by analyses of their HPLC performance, UV-vis and FTIR spectra. The most possible photocatalytic degradation mechanism was discussed in detail. Of the dyes available on the market today, about $60-70 \%$ is azo compounds and azo-dye Orange II is selected as the model pollutant due to its sensitivity to oxidative and reductive species during degradation.

\section{Experimental}

\subsection{Materials}

Orange II and $\mathrm{TiO}_{2}$ were purchased from Beijing Chemical Reagents Company. Orange II was selected as a model pollutant and used without further purification. $\mathrm{TiO}_{2}$ used for the preparation of $\mathrm{TiO}_{2}$ modified $\beta-\mathrm{PbO}_{2}$ electrode was pure anatase. Other materials used in the test were of analytical grade. Deionized and doubly distilled water was used throughout the study. The preparation and other properties of the electrode can be referred to the related study [11].

\subsection{Electrochemically assisted photocatalytic degradation of Orange II}

The electrochemically assisted photocatalytic degradation of Orange II was carried out in a semi-cylindrical quartz reactor. Titanium wire was used as the cathode and the effective working area of anode was $20 \mathrm{~cm}^{2} . \beta-\mathrm{PbO}_{2}$ electrode modified by $\mathrm{TiO}_{2}$ was used as the photoanode. The available volume of the reactor was $150 \mathrm{~mL}$ and $125 \mathrm{~mL}$ simulated dye wastewater (Orange II with a concentration of $25 \mathrm{mg} / \mathrm{L}$ ) was added. An $8 \mathrm{~W}$ low pressure UV lamp emitting a wavelength of $254 \mathrm{~nm}$ was situated parallel to the electrodes at a distance of $20 \mathrm{~mm}$ from the quartz reactor. The potential applied across the electrodes was $1.5 \mathrm{~V}$. The dye solution was stirred vigorously by a magnetic stirrer.

\subsection{Analyses}

The solution $\mathrm{pH}$ values were adjusted with $\mathrm{NaOH}$ or $\mathrm{HCl}$ using an Orion 720APLUS Benchtop meter (Thermo Orion Co., USA). The UV-vis spectra of the samples were recorded from 200 to $600 \mathrm{~nm}$ using a U-3010 UV-vis spectrophotometer (Hitachi Co., Japan). The concentration of the dye was determined by measuring the absorbance at a fixed wavelength $(484 \mathrm{~nm})$, which corresponded to the maximum absorption wavelength of Orange II in visible region.

Total organic carbon (TOC) in water was measured by a multi N/C 3000 (AnalytikJenaAG, Germany) after the solution was filtered through a $0.45 \mu \mathrm{m}$ filter. The stable voltage was supplied by a DH1715A-3 potentiostat (Beijing Dahua Radio Instrument Factory). The FT-IR spectra of Orange II and the final products under different $\mathrm{pH}$ conditions were recorded on a Thermo Nicolet NEXUS 670 FT-IR spectrometer.

Analyses of Orange II and its degradation products were also carried out on a high-performance liquid chromatograph (HPLC, Hitachi, Japan). Aliquots of $20 \mu \mathrm{L}$ were injected to the HPLC, running with the mobile phase of acetonitrile/water $(0.025 \mathrm{~mol} / \mathrm{L}$ ammonium acetate $)(\mathrm{v} / \mathrm{v})$ at $25 / 75$. The separation was performed using an ODS-25u reversed phase column (Alltech, USA) at the flow rate of $1.0 \mathrm{~mL} / \mathrm{min}$ and column temperature of $40^{\circ} \mathrm{C}$. Most of the aromatic intermediates detected in this study have strong absorbance at around $254 \mathrm{~nm}$ and thereafter a diode array detector was used with the wavelength set at $254 \mathrm{~nm}$.

\section{Results and discussion}

\subsection{Effect of solution $\mathrm{pH}$ on the removal of color and TOC}

Potential values for the couple $\mathrm{OH}^{\bullet} / \mathrm{OH}^{-}$and $\mathrm{OH}^{\bullet}, \mathrm{H}^{+} / \mathrm{H}_{2} \mathrm{O}$ are +1.9 and $+2.7 \mathrm{~V}$, respectively [12]. The potential applied across the electrodes was $1.5 \mathrm{~V}$ in this research and $\mathrm{OH}^{\bullet}$ radicals could not be formed by anodic oxidation under the conditions examined. In addition, due to the absence of supporting electrolyte in solution, the effect of electrolysis was further limited, which was proved by our related study. Color removal was mainly attributed to photocatalytic degradation in the experiments involved.

Both the acidic and alkaline conditions favored color removal and almost the complete removal of color was realized in electrochemically assisted photocatalytic degradation process at $120 \mathrm{~min}$, as illustrated in Fig. 1. The removal of color only achieved $66.5 \%$ in neutral solution within the same period. It is known that $\mathrm{pH}$ values can influence the adsorption of dye molecules onto the catalyst surfaces. The efficiency of photocatalytic process strongly depends upon the $\mathrm{pH}$ of the reaction media [13] and Orange II was expected to be decolorized at the highest rate due to its strong adsorption on $\mathrm{TiO}_{2}$ in acidic solution. Nevertheless, fast decoloration was achieved at $\mathrm{pH} 2.29$ as 


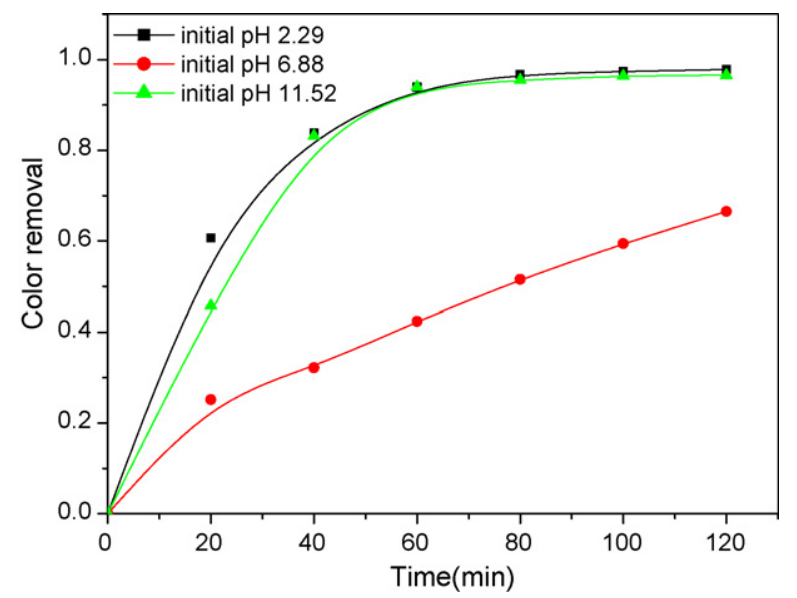

Fig. 1. The pH-dependence of the color removal as a function of the irradiation time at $\mathrm{pH} 2.29,6.88$ and 11.52 by 2 -h treatment.

well as at $\mathrm{pH} 11.52$ in this experiment and this might be partly attributed to the application of the electric field.

Besides the removal of color, the removal of TOC was another important parameter which should be investigated in photocatalytic degradation process, but it was not frequently studied in the previous literature. The removal of TOC at $\mathrm{pH} 2.29$ was $20.0 \%$ higher as compared with that at $\mathrm{pH} 11.52$, though the color was almost completely removed under the two conditions. It can be concluded that complete decoloration does not mean complete mineralization and the fast decoloration rate is not always correlated with the high TOC removal. The simulated azo-dye wastewater was more easily to be completely discolored than to be completely mineralized. High TOC removal favors the reduction of all the toxicity of the wastewater and it is better to select a suitable operating condition to mineralize azo dyes more completely rather than to only remove all the color [14]. Hence, acidic condition is the best $\mathrm{pH}$ condition for the decontamination of the dye.

\section{2. pH-dependence on the effect of hole process}

Iodide ion is used to scavenge valence band holes and adsorbed hydroxyl radicals, which is usually accepted as a diagnostic tool for suppressing the hole process [15]. In the presence of KI $(0.002 \mathrm{~mol} / \mathrm{L})$, the influence of current will become significant to some extent and one might argue that the increased removal of color could be attributed to the increased effect of electrolysis. To rule out this effect, degradation of Orange II was also conducted in the presence of $\mathrm{KCl}(0.002 \mathrm{~mol} / \mathrm{L})$ at $\mathrm{pH} 2.29$ and 11.52. The effect of $\mathrm{KI}$ and $\mathrm{KCl}$ was compared in Fig. 2. Additionally, the influence of chloride ions was complex in the process. On the one hand, the removal of color will increase in the presence of $\mathrm{KCl}$ as a result of the increased current. On the other hand, chloride ions have been found to be the scavengers for the heterogeneous photocatalytic process by competing for surface active sites and forming the weaker radicals, which is proposed as following:

$\mathrm{Cl}^{-}+\mathrm{h}^{+} \rightarrow \mathrm{Cl}^{\bullet}$

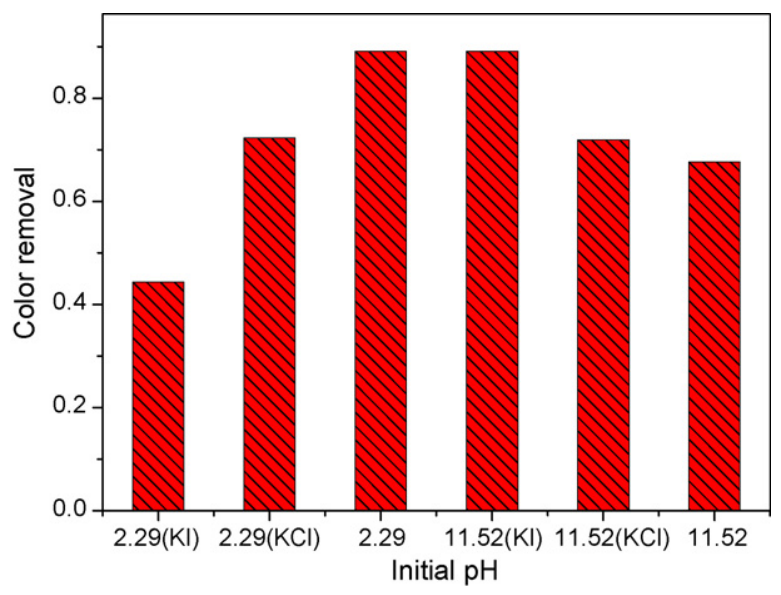

Fig. 2. Color removal at $40 \mathrm{~min}$ in the solutions at $\mathrm{pH} 2.29$ and 11.52 in the presence and absence of $\mathrm{KI}$ or $\mathrm{KCl}$ with a concentration of $0.002 \mathrm{~mol} / \mathrm{L}$.

$\mathrm{Cl}^{-}+\mathrm{OH}^{\bullet} \rightarrow \mathrm{ClOH}^{\bullet-}$

$[16,17]$. If the strong reductive ability of KI was excluded, the effect of $\mathrm{KI}$ and $\mathrm{KCl}$ should be quite close. As illustrated in Fig. 2, the influence of KI was more profound as compared with that of $\mathrm{KCl}$ and the effect of $\mathrm{KI}$ was evident.

It was expected that the photocatalytic degradation of Orange II will be greatly inhibited in the presence of KI if photocatalytic oxidation predominated despite the difference of reaction media. At pH 2.29, the removal of color declined from $89.0 \%$ in the absence of KI to $44.3 \%$ in the presence. This indicated that valence band holes and adsorbed hydroxyl radicals had been effectively scavenged by KI. Conversely, the removal of color increased by $21.5 \%$ in the presence of $\mathrm{KI}$ at $\mathrm{pH} 11.52$ and consequently different degradation mechanism was involved. Meanwhile, it proved that there should be other species which contributed to the removal of color besides the oxidative species such as active holes and hydroxyl radicals under alkaline condition.

\subsection{Destruction of the chromophores of Orange II}

Orange II has four absorbance bands in which two bands in visible region and two in ultraviolet region. The structure of Orange II is illustrated in the inset of Fig. 3(a). In visible region, a major band locates at $484 \mathrm{~nm}$ and a shoulder band at $430 \mathrm{~nm}$ due to the hydrazone form and azo form of Orange II, respectively. The other two bands at 230 and $310 \mathrm{~nm}$ in ultraviolet region are ascribed to the benzene and naphthalene rings of the dye, respectively $[18,19]$. The changes of the peaks reflect the evolution of the chromophores of Orange II and useful information could be provided by analysis of the UV-vis spectra. The $\mathrm{UV}$-vis spectral changes taking place as a function of irradiation time were illustrated in Fig. 3. The spectral changes at $\mathrm{pH} 6.88$ were similar to that at $\mathrm{pH} 2.29$ but its evolution was comparatively slower. Therefore, only the spectral changes at $\mathrm{pH} 2.29$ and 11.52 were compared. The four absorbance bands of Orange II disappeared after 120 min degradation in both solutions, which indicated that the dye structure was totally destructed. Nevertheless, there was a new absorbance peak at ca. $255 \mathrm{~nm}$ generated 

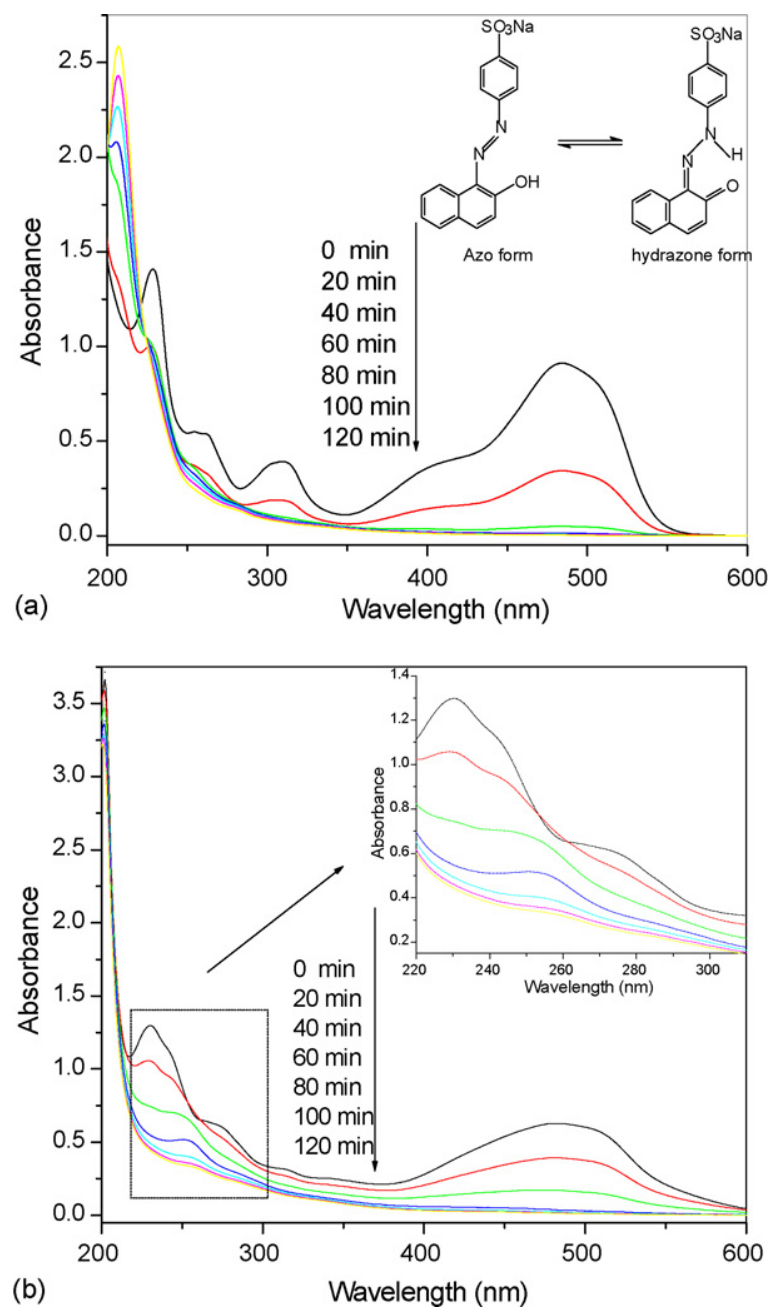

Fig. 3. UV-vis spectral changes as a function of the irradiation time at $\mathrm{pH} 2.29$ (a) and 11.52 (b).

at about $40 \mathrm{~min}$ at $\mathrm{pH} 11.52$, which shrank itself once it was formed, as shown in the inset of Fig. 3(b). This consisted of the major difference between the two solutions at $\mathrm{pH} 2.29$ and 11.52 and proved that some chemicals were produced in large quantity at the very beginning of reaction due to their susceptibility to oxidative species.

\subsection{Analysis of the degradation products}

In view of the difference of the $\mathrm{UV}-\mathrm{vis}$ spectra at $\mathrm{pH} 2.29$ and 11.52 , intermediates produced in solutions at different $\mathrm{pH}$ values may change in different trends, and therefore their contents as a function of time were measured by HPLC, which is presented in Fig. 4. The most obvious difference between solutions at $\mathrm{pH}$ 2.29 and 11.52 was the changes of the intermediate corresponded with retention time $\left(t_{\mathrm{R}}\right)$ at $1.9 \mathrm{~min}$. At $\mathrm{pH} 11.52$, the intermediate with $t_{\mathrm{R}}$ at $1.9 \mathrm{~min}$ firstly accumulated to its peak value and then decreased steadily. Its changing curve was the most well-defined and the intermediate distinguished itself from the other ones by its highest intensity among the intermediates all through the process. The increase of the intensities of the other intermediates at 2.0, 2.7 and 4.3 min was not so obvious. The changing curve
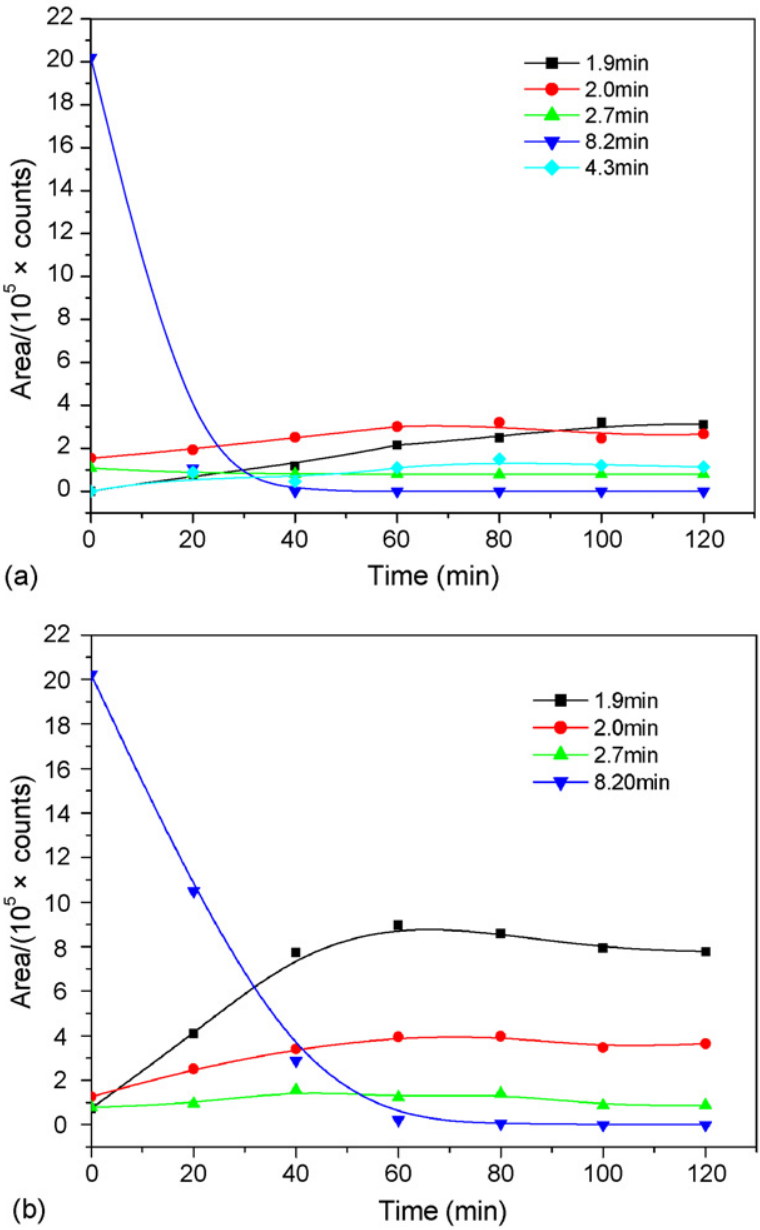

Fig. 4. Intensity changes of reaction products as a function of time at $\mathrm{pH} 2.29$ (a) and 11.52 (b)

for the intermediate at 1.9 min was not well-defined at all at $\mathrm{pH}$ 2.29. What should be mentioned is that there were other two intermediates at 3.8 and 4.3 min produced at $\mathrm{pH} 2.29$, in which the intermediate at $3.8 \mathrm{~min}$ was negligible. Nevertheless, the two intermediates at 3.8 and 4.3 min were not determined at $\mathrm{pH} 6.88$ and 11.52 .

In addition, the contents of the reaction products varied in the final solutions based on the results obtained above, which may be reflected by their FTIR spectra. Fig. 5 illustrates the FTIR spectra of the products remaining in the final solutions at $\mathrm{pH} 2.29$, 6.88 and 11.52. The bands located at $1600-1450 \mathrm{~cm}^{-1}$ (aromatic $\mathrm{C}=\mathrm{C}$ stretching $), 1623 \mathrm{~cm}^{-1}(\mathrm{C}=\mathrm{N}$ stretching $), 1508 \mathrm{~cm}^{-1}$ (N-H bending), $1452 \mathrm{~cm}^{-1}$ (N-N stretching), $1000-1250 \mathrm{~cm}^{-1}$ ( $\mathrm{S}-\mathrm{O}$ stretching and aromatic $=\mathrm{C}-\mathrm{H}$ bending), respectively represent the characteristic absorption of Orange II in the infrared band [20]. Obviously, there was a new absorption peak of $1640 \mathrm{~cm}^{-1}$ generated for the products under the three $\mathrm{pH}$ conditions examined, which can be assigned as the $\mathrm{C}=\mathrm{O}$. In addition, a new peak at $1382 \mathrm{~cm}^{-1}\left(-\mathrm{NO}_{2}\right.$ stretching $)$ appeared for the three samples, which was very clear though it was weak. The above proved that photocatalytic oxidation occurred all through the process despite the influence of solution $\mathrm{pH}$. The strong absorption at $1623 \mathrm{~cm}^{-1}$ still remained and other vibrations became 


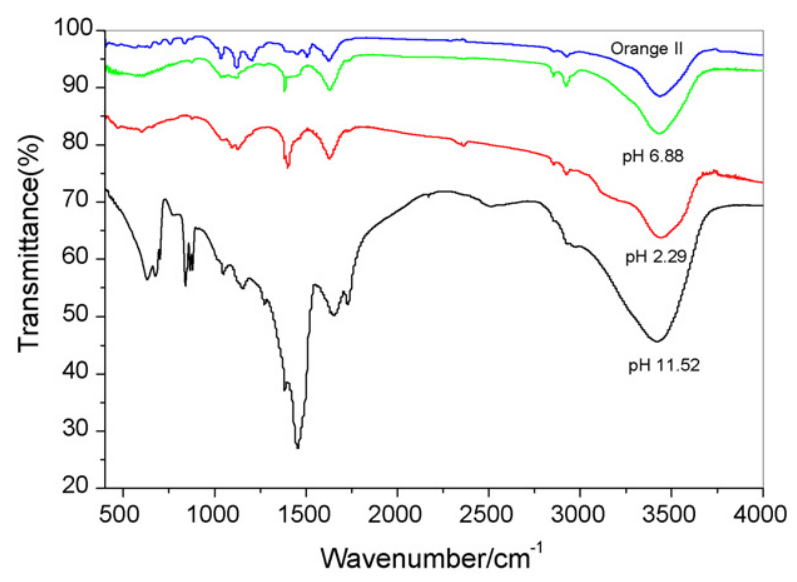

Fig. 5. FTIR spectra of Orange II and the final products in solutions at $\mathrm{pH} 2.29$, 6.88 and 11.52 .

very weak or even disappeared for the three samples after degradation. This indicated that the drastic destruction of the dye occurred but the aromatic $\mathrm{C}=\mathrm{N}$ groups were not completely decomposed in the final solutions at $\mathrm{pH} 2.29,6.88$ and 11.52. For the FTIR spectra corresponded with the final solutions at $\mathrm{pH}$ 2.29 , there were new bands at 1400 and $2300-2400 \mathrm{~cm}^{-1}$ generated. Both the bands may be associated to $\mathrm{COx}$ species such as $\mathrm{CO}_{3}{ }^{2-}$ and $\mathrm{HCO}_{3}{ }^{-}[21,22]$. There were not such evident bands present in the spectra corresponded with the other two final solutions at pH 6.88 and 11.52, which indicated that more complete destruction was achieved in acidic solution. These chemicals may be corresponded with the two intermediates with $t_{\mathrm{R}}$ at 3.8 and $4.3 \mathrm{~min}$ in HPLC analysis at $\mathrm{pH} 2.29$. Unique bands at 1154 , $1270,1457 \mathrm{~cm}^{-1}$ (aromatic $\mathrm{C}=\mathrm{C}$ stretching) and $1727 \mathrm{~cm}^{-1}$ $(\mathrm{C}=\mathrm{O}$ stretching) appeared in the FTIR spectra corresponded with the final solutions at $\mathrm{pH} 11.52$. The strongest absorption at $1457 \mathrm{~cm}^{-1}$ indicated that the aromatic rings were still kept intact to a large extent. This implied that Orange II was destructed more incompletely in solution at $\mathrm{pH} 11.52$ compared with at $\mathrm{pH}$ 2.29. Totally, photocatalytic oxidation occurred in the three solutions despite the influence of the initial $\mathrm{pH}$ values, but the dye was oxidized to an especially different extent under the three $\mathrm{pH}$ conditions.

\subsection{Reaction pathways of electrochemically assisted photocatalytic degradation of Orange II}

Although the influence of the initial $\mathrm{pH}$ values in the process was complex, only $\mathrm{TiO}_{2}$ particles and Orange II molecules were involved during degradation. From this point of view, the initial $\mathrm{pH}$ condition had exerted its influence on the following two aspects. One was that the properties of $\mathrm{TiO}_{2}$ particles on the electrode might have varied according to the changes of the initial $\mathrm{pH}$ values and thus the effect of photocatalytic oxidation was apparently different. The other was that the characteristics of the dye might have changed under the three $\mathrm{pH}$ conditions examined.

Under different $\mathrm{pH}$ conditions, hydroxyl groups on $\mathrm{TiO}_{2}$ surface undergo the following equilibrium through Lewis acid-base reaction [23]:

$$
\begin{aligned}
& \mathrm{pH}<\mathrm{PZC}: \mathrm{TiOH}+\mathrm{H}^{+} \leftrightarrow \mathrm{TiOH}_{2}{ }^{+} \\
& \mathrm{pH}>\mathrm{PZC}: \mathrm{TiOH}+\mathrm{OH}^{-} \leftrightarrow \mathrm{TiO}^{-}+\mathrm{H}_{2} \mathrm{O}
\end{aligned}
$$

The point of zero charge (PZC) of the $\mathrm{TiO}_{2}$ (Degussa $\left.\mathrm{P}-25\right)$ is at $\mathrm{pH}$ 6.8. The anatase content is $80 \%$ for Degussa $\mathrm{P}-25 . \mathrm{TiO}_{2}$ used for the preparation of the electrode is pure anatase and it could be deduced that the $\mathrm{PZC}$ for the pure anatase $\mathrm{TiO}_{2}$ is about 6.8 [24]. $\mathrm{TiO}_{2}$ surface is positively charged in acidic media $(\mathrm{pH}<6.8)$ and negatively charged under alkaline conditions $(\mathrm{pH}>6.8)$. For Orange II, $\mathrm{p} K_{\mathrm{a}_{1}}$ value for the deprotonation of the naphthalene $\mathrm{OH}$ is 11.4 and $\mathrm{p} K_{\mathrm{a}_{2}}$ value for the deprotonation of $\mathrm{SO}_{3} \mathrm{H}$ group is $\sim 1$ from the literature [25]. Orange II molecules are negatively charged at almost all the $\mathrm{pH}$ range studied. Therefore, the lower the solution $\mathrm{pH}$ values, the stronger the adsorption of the dye on $\mathrm{TiO}_{2}$ surface is as a result of electrostatic forces, which is well documented in the literature [2].

Photocatalytic degradation of dye is thought to be dominated by catalytic oxidation as far as color removal is concerned. Not only the removal of color but also the removal of TOC can be realized by photocatalytic oxidation. A series of oxidative species such as $\mathrm{OH}^{\bullet}, \mathrm{O}_{2}^{\bullet-}$ and ${ }^{\bullet} \mathrm{OOH}$ are regarded as the products of conduction band electrons and valence band holes [2]:

$$
\begin{aligned}
& \mathrm{TiO}_{2}+h v \rightarrow \mathrm{TiO}_{2}\left(\mathrm{~h}^{+}+\mathrm{e}^{-}\right) \\
& \mathrm{h}^{+}+\mathrm{H}_{2} \mathrm{O}\left(\mathrm{OH}^{-}\right) \rightarrow \mathrm{OH}^{\bullet}+\mathrm{H}^{+} \\
& \mathrm{e}^{-}+\mathrm{O}_{2} \rightarrow \mathrm{O}_{2}^{\bullet-} \\
& \mathrm{O}_{2}^{\bullet-}+\mathrm{H}^{+} \rightarrow \bullet \mathrm{OOH}
\end{aligned}
$$

In fact, the lifetime of trapped conduction-band electrons is much longer than that of valence band holes or hydroxyl radicals, which can be seen from the characteristic time of interfacial charge transfer step [1]:

$$
\left\{\mathrm{Ti}^{\mathrm{IV}} \mathrm{OH}^{\bullet}\right\}^{+}+\mathrm{Red} \rightarrow>\mathrm{Ti}^{\mathrm{IV}} \mathrm{OH}+\operatorname{Red}^{\bullet+} \text { slow }(100 \mathrm{~ns})
$$

$\mathrm{e}_{\mathrm{tr}}{ }^{-}+\mathrm{Ox} \rightarrow \mathrm{Ti}^{\mathrm{IV}} \mathrm{OH}+\mathrm{Ox}^{\bullet-}$ very slow (ms)

The characteristic time of $\mathrm{h}_{\mathrm{vb}}{ }^{+}$is only $10 \mathrm{~ns}$. Hence, conductionband electrons are expected to shift the longest distance into bulk solution. They are the most probable species to be scavenged by Orange II. There was not a large amount of oxygen present in the solutions, which facilitated the reaction between Orange II molecules and active electrons. In addition, photocatalytic oxidation process was proved to have been enhanced by the combination with electrochemical process. In the presence of an electric field, charge carriers were proved to be effectively separated by the application of an anodic bias to a $\mathrm{TiO}_{2}$ film electrode, which consequently enhanced photocatalytic efficiency $[6,26]$. $\mathrm{TiO}_{2}$ particles immobilized on $\beta-\mathrm{PbO}_{2}$ electrode could not agglomerate under the $\mathrm{pH}$ conditions examined. More effective separation of active holes and electrons was realized on $\mathrm{TiO}_{2}$ modified $\beta-\mathrm{PbO}_{2}$ electrode and the lifetime of active electrons were enlarged to a great extent, which favored the reductive cleavage of Orange II molecules in the vicinity of the cathode. 
On the other hand, azo bond is more easily to be reduced by reductive species such as active electrons or active hydrogen atoms compared with the other groups in azo dye structure. Once the azo bond is cleaved, the conjugated structure of azo dye is destructed, accompanied by the complete color removal in the visible region rather than TOC removal $[27,28]$. Sulfanilamide and 1-amino-2-naphtol are the most probable products resulted from electrons or active hydrogen atoms reduction, among which 1-amino-2-naphtol is the most possible chemical susceptible to oxidative species. As we know, substituted $o$ aminohydroxynaphthalenes were oxygen-sensitive and easy to be oxidized into chemicals with carbonyls when exposed to air, which was well accepted as auto-oxidation [29]. Both 1-amino2-naphtol and $o$-aminohydroxynaphthalenes were resulted from the reductive cleavage of azo-dye and they shared a hydroxyl group like phenol. Accordingly, one of the most possible intermediates 1-amino-2-naphtol may be immediately oxidized into chemicals with carbonyls by oxidants stronger than oxygen, which might have presented their characteristic absorbance at $255 \mathrm{~nm}$. Furthermore, Kuramitz et al. [30] investigated the electrochemical oxidation of bisphenol A by voltammetric techniques using a glassy carbon electrode. They found that the oxidation wave of bisphenol A shifted to lower potentials with increasing $\mathrm{pH}$ especially at $\mathrm{pH} 9.4$ since the $\mathrm{p} K_{\mathrm{a}}$ of bisphenol $\mathrm{A}$ is 9.8, which demonstrated that the phenolate ion is oxidized more easily than neutral bisphenol A. For Orange II, $\mathrm{p} K_{\mathrm{a}_{1}}$ value for the deprotonation of the naphthalene $\mathrm{OH}$ is 11.4 and it may be deduced that Orange II is more easily oxidized at $\mathrm{pH} 11.52$. In fact, quinonic compounds have a characteristic UV-vis absorption at around $255 \mathrm{~nm}$ [31]. Therefore, reductive degradation mechanism is suggested to explain the special phenomena in this experiment.

Under acidic condition, more and more dye molecules were adsorbed on the photoanode and then decomposed by the oxidative species. Though the dye can be decomposed by the active electrons and active hydrogen atoms under this condition, the effect of the reductive species may be still negligible by contrast with that of the oxidative species due to the strong adsorption of the dye on $\mathrm{TiO}_{2}$ of the photoanode. The highest TOC removal at $\mathrm{pH} 2.29$ proved the high efficiency of photocatalytic oxidation process. Oxidative species such as active holes and adsorbed $\mathrm{OH}$ radicals were greatly suppressed in the presence of $\mathrm{KI}$ at $\mathrm{pH} 2.29$, resulting in the lower decoloration rate. This is consistent with the phenomenon observed above.

At $\mathrm{pH} 11.52$, very weak adsorption occurred between photoanode and the dye molecules, and thereafter the direct oxidation of the dye on the photoanode was partly inhibited. More and more dye molecules were reductively decomposed by the increasing number of reductive species in the vicinity of cathode. A significant proportion of decoloration was attributed to the reductive degradation. However, reductive degradation can only lead to the decomposition of the conjugated structure of azo dye but the removal of organic carbon. The dye was not oxidized so completely at $\mathrm{pH} 11.52$ as at $\mathrm{pH} 2.29$ in $2 \mathrm{~h}$. As a result, the removal of TOC was especially lower at $\mathrm{pH} 11.52$ than that at $\mathrm{pH}$ 2.29. When KI was added into the solution

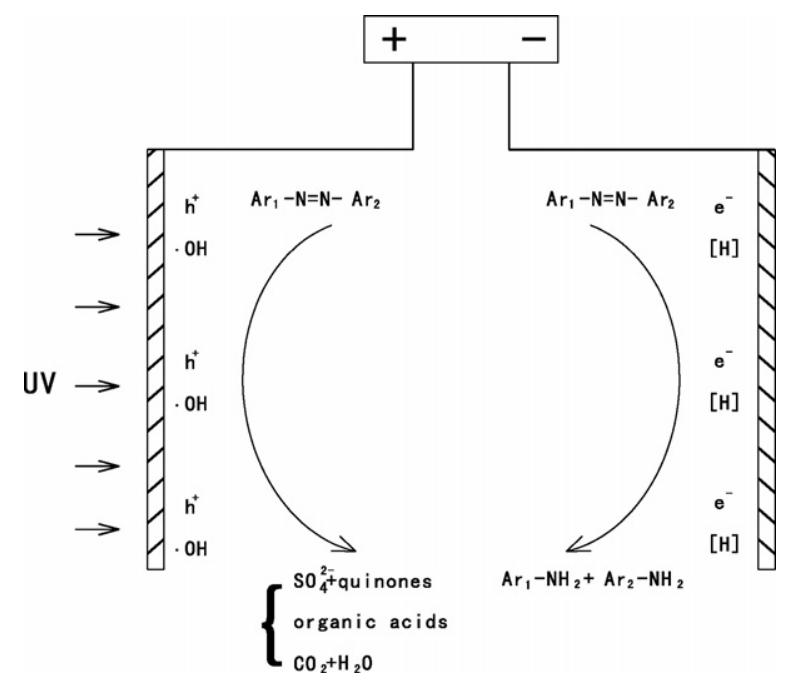

Fig. 6. Illustration of the simplified pathways for the electrochemically assisted photocatalytic degradation of azo-dye Orange II $\left(\mathrm{Ar}_{1}-\mathrm{N}=\mathrm{N}-\mathrm{Ar}_{2}\right)$.

at $\mathrm{pH} 11.52$, the effect of the oxidative species was further suppressed but the effect of the reductive species was greatly enhanced due to the lower recombination probability with oxidative species. Therefore, the total removal of color was increased as well at $\mathrm{pH} 11.52$. Totally, initial $\mathrm{pH}$ condition had only exerted its influence on the photocatalytic degradation process to some extent and the efficiency was changed consequently. The high TOC removal at $\mathrm{pH} 2.29$ and 11.52 also proved that photocatalytic oxidation dominated the process from the beginning of the reaction. The general mechanism of electrochemically assisted photocatalytic degradation of Orange II is illustrated in Fig. 6.

\section{Conclusions}

The performance for the degradation of Orange II was greatly dependent on the initial $\mathrm{pH}$ values especially in terms of the removal of color and TOC in the process of electrochemically assisted photocatalytic degradation. Similar removal rate of color was achieved at $\mathrm{pH} 2.29$ and $11.52 \mathrm{in} 2 \mathrm{~h}$, but the removal of TOC at $\mathrm{pH} 11.52$ was especially lower than that at $\mathrm{pH} 2.29$. Orange II was oxidized more completely at $\mathrm{pH} 2.29$ than at the other two $\mathrm{pH}$ values. The effect of reductive species such as active electrons was proved to be significant at $\mathrm{pH} 11.52$. The application of an electric field facilitated the separation of charge carriers and a reductive degradation pathway by active electrons was proposed, which only lead to the removal of color of the visible region in parallel with the oxidative degradation pathway. Initial $\mathrm{pH}$ values were proved to have only partly influenced the degradation pathways and thus the dye was still mineralized to different extent.

\section{Acknowledgement}

The authors appreciate the financial support of National Natural Science Fund for Distinguished Young Scholars (No. 50225824). 


\section{References}

[1] M.R. Hoffmann, S.T. Martin, W. Choi, D.W. Bahnemann, Chem. Rev. 95 (1995) 69

[2] I.K. Konstantinou, T.A. Albanis, Appl. Catal. B: Environ. 49 (2004) 1

[3] A.L. Linsebigler, G.Q. Lu, J.T. Yates Jr., Chem. Rev. 95 (1995) 735.

[4] O. Legrini, E. Oliveros, A.M. Braun, Chem. Rev. 93 (1993) 671.

[5] X.Z. Li, H.L. Liu, P.T. Yue, Y.P. Sun, Environ. Sci. Technol. 34 (2000) 4401.

[6] K. Vinodgopal, S. Hotchandani, P.V. Kamat, J. Phys. Chem. 97 (1993) 9040.

[7] M.D. Ward, A.J. Bard, J. Phys. Chem. 86 (1982) 3599.

[8] M.V.B. Zanoni, J.J. Sene, M.A. Anderson, J. Photochem. Photobiol. A: Chem. 157 (2003) 55.

[9] H.Q. Zhang, K.C. Chen, T. He, Dyes Pigments 37 (1998) 241.

[10] C. Bauer, P. Jacques, A. Kalt, Chem. Phys. Lett. 307 (1999) 397.

[11] G.T. Li, J.H. Qu, X.W. Zhang, J.T. Ge, Water Res. 40 (2006) 213.

[12] U. Schumann, P. Grundler, Water Res. 32 (1998) 2835.

[13] M.A. Fox, M.T. Dulay, Chem. Rev. 93 (1993) 341.

[14] J.Y. Feng, X.J. Hu, P.L. Yue, Environ. Sci. Technol. 38 (2004) 5773.

[15] J. Rabani, K. Yamashita, K. Ushida, J. Stark, A. Kira, J. Phys. Chem. B. 102 (1998) 1689.

[16] M. Abdullah, G.K.-C. Low, R.W. Matthews, J. Phys. Chem. 94 (1990) 6820 .
[17] H.Y. Chen, O. Zahraa, M. Bouchy, J. Photochem. Photobiol. A: Chem. 108 (1997) 37.

[18] F. Wu, N.S. Deng, H.L. Hua, Chemosphere 41 (2000) 1233.

[19] M. Stylidi, D.I. Kondarides, X.E. Verykios, Appl. Cata. B: Environ. 40 (2003) 271

[20] L. Lucarelli, V. Nadtochenko, J. Kiwi, Langmuir 16 (2000) 1102.

[21] M. Stylidi, D.I. Kondarides, X.E. Verykios, Appl. Catal. B: Environ. 47 (2004) 189

[22] R.C. Wu, J.H. Qu, H. He, Y.B. Yu, Appl. Catal. B: Environ. 48 (2004) 49.

[23] K. Nohara, H. Hidaka, E. Pelizzetti, N. Serpone, Photochem. Photobiol. A: Chem. 102 (1997) 265

[24] I. Poulios, I. Tsachpinis, J. Chem. Technol. Biotechnol. 74 (1999) 349.

[25] J. Bandara, J.A. Mielczarski, J. Kiwi, Langmuir 15 (1999) 7670.

[26] M.D. Ward, A.J. Bard, J. Phys. Chem. 86 (1982) 3599.

[27] X.J. Peng, J.Z. Yang, J.T. Wang, Dyes Pigments 20 (1992) 73

[28] Z. Mandic, B. Nigovic, B. Simunic, Electrochim. Acta 49 (2004) 607.

[29] M. Kudlich, M.J. Hetheridge, H.-J. Knackmuss, A. Stolz, Environ. Sci. Technol. 33 (1999) 896.

[30] H. Kuramitz, Y. Nakata, M. Kawasaki, S. Tanaka, Chemmosphere 45 (2001) 37.

[31] L. Huang, D.Q. Yu, Application of UV-vis Spectra in Organic Chemistry, Science Press, Beijing, 1988 